ORIGINAL ARTICLE

\title{
Risk of hip fracture in protected and unprotected falls in nursing homes in Norway
}

\author{
L Forsén, A J Søgaard, S Sandvig, A Schuller, U Røed, C Arstad
}

Injury Prevention 2004;10:16-20. doi: 10.1136/ip.2003.003889

See end of article for authors' affiliations

.....................

Correspondence to: Lisa Forsén, Division of Epidemiology, Norwegian Institute of Public Health, Post Box 4404, Nydalen, 0403 Oslo, Norway: lisa.forsen@fhi.no
A lmost $100 \%$ of hip fractures are the result of a fall. ${ }^{12}$ Since 1993 several studies have shown that an external hip protector can prevent many hip fractures in high risk groups, ${ }^{3-5}$ but its protection is not necessarily $100 \% .^{267}$ When a person is so osteoporotic that the hip can break just by walking, or the person falls backward, the hip protector cannot protect effectively against hip fracture. The majority of patients with hip fracture $(76 \%)$, however, seem to fall directly to the side, ${ }^{2}$ and a fracture might then be prevented by use of a hip protector.

The present paper is the second from a hip protector intervention project in Norway. The first paper dealt with the reduction of incidence of hip fracture (an intention to treat analysis ${ }^{6}$ ), while this second paper deals with protected and unprotected falls. The intervention project took place in two municipalities outside Oslo (Asker and Bærum). Hip protectors were introduced as a regular part of the health care service for all residents in 17 nursing homes for an intervention period of 18 months. In the first paper an external and independent evaluation showed a 39\% reduction in the incidence of hip fracture in these nursing homes during the intervention period compared with an 18 month pre-intervention period. ${ }^{6}$

The results from this project, as well as other hip protector intervention studies, are dependent on both patient compliance in the intervention group and on the real effect of the hip protector in a given fall. In addition the results will be dependent on the degree to which the user group of the hip protector contains most of the high risk people in the intervention group. In the Asker/Bærum project the intervention group contained both high risk and low risk individuals-that is, all the residents were offered hip protectors. ${ }^{6}$ Knowledge about the ability of the hip protector to reduce the incidence of hip fracture in a high risk group is important and interesting for health care authorities. This is the case irrespective of whether the hip fracture decrease is due mainly to good compliance and/or good protective effect in a given fall. However, for a high risk person and his or her doctor it is also interesting to know how effectively the hip protector protects against hip fracture in a given fall.

The aim of this second paper from the Asker/Bærum project was therefore to compare the probability of hip fracture in protected and unprotected falls among the fallers in nursing homes where all the residents were offered hip protectors.

\section{METHODS}

\section{Study design and intervention}

The data from the Asker/Bærum project, the implementation of the hip protector in the 17 nursing homes (965 beds), and the registration of hip fractures (that is, fractura colli femoris and fractura pertrochanterica) in the nursing homes during the 18 month intervention period have been described elsewhere. ${ }^{6}$ During the whole intervention period, the employees in 15 of the 17 nursing homes (790 beds) filled out a questionnaire each time a fall had occurred among the residents and judged whether the hip protector, if worn, was in place at the time of the fall. The questionnaire also contained a question about whether the resident was a regular user of hip protectors: "No, never", "Yes during the day", "Yes during the night", "Yes 24 hours a day". A fall was defined as the resident having unintentionally landed on the floor or on the ground. The residents were allowed to change user status during the intervention period as often as they wanted to because the project was not a research project. If for example a non-user of hip protectors fell and therefore wanted to be a user, he or she was registered as a user after that fall. All the registered users were offered a hip protector (underwear with protection pads) every morning and also new ones during the day if necessary. Each time a new resident moved into the nursing home he or she was offered

Abbreviations: $\mathrm{Cl}$, confidence interval; $\mathrm{OR}$, odds ratio 
hip protectors and was then registered as a user or non-user of hip protectors. All the hip protectors were washed in the joint laundry. When a resident died he or she was of course out of the observation of falls, but all the falls registered for him or her were kept in the analysis.

The fallers (residents with at least one fall during the intervention period) with known hip protector status (use/no use) in their first registered fall (705 residents of a total of 790 residents with a first fall during the intervention period) were selected for the analysis in the present paper. We have information about age and gender, whether they were users or not of hip protectors at the time of their first fall, their wearing or not wearing of a hip protector in their first fall, and a resulting hip fracture or not in their first fall. All the hip fractures were confirmed in patient records in Bærum hospital, where all residents sustaining a hip fracture were sent. Since this project was not a research project, information about frailty of the residents was not collected, and the employees were too busy to fill out more questionnaires.

The Data Inspectorate of Norway and the Norwegian Board of Health approved the study, and the proposal was presented to the Regional Committee for Medical Research Ethics.

\section{Statistical analyses}

The odds ratio (OR) of breaking the hip for fallers wearing a hip protector in their first fall compared to fallers who were registered as users of hip protectors but who did not wear the hip protector in their first fall was estimated by means of logistic regression.

The frailest of the residents were especially encouraged to use the hip protector, which resulted in a difference in frailty among users and non-users.

Frailty is defined here as having fall tendency and/or established osteoporosis or other risk factors for hip fracture (for example, leanness), but the categorisation of residents being frail or not was only based on the employees' subjective knowledge of the resident and the resident's own judgment (if possible). This frailty was adjusted for in the analysis by including "hip protector user status" in the logistic regression model. "Hip protector user status" was defined as follows:

- "User-not wearing protector": registered users at the time of their first fall, not wearing the hip protector in this fall.

- "User-wearing protector": registered users in their first fall, wearing the hip protector in this fall.

- "Non-user" at the time of their first fall.

These three exclusive groups constituted a nominal variable called "hip protector status". With "user-not wearing protector" as the reference category we adjusted for user status when comparing the risk of hip fracture in the first fall between wearers and non-wearers. Both the employees and the residents themselves had judged the registered users of hip protectors to be at particularly high risk of hip fracture. This is the only information of frailty we have in this study and is therefore the only frailty information we were able to adjust for in the logistic regression model

\section{RESULTS}

Four hundred and thirty (61\%) of the 705 fallers were nonusers of hip protectors, while 84 (12\%) were users, but did not wear it, and $191(27 \%)$ were users and did wear it in their first fall. Nearly $70 \%$ of the registered users wore hip protector in their first fall $(191 /(191+84)=69.5 \%)$ (table 1).

Both the registered users wearing hip protectors and the non-users had a percentage of breaking the hip about a third
Table 1 Number of fallers, number of fractures, and incidence of fractures in the first registered fall within each of 705 fallers in 15 nursing homes in two municipalities in Norway in 1998/99 according to age, gender, and hip protector status* (unadjusted association)

\begin{tabular}{|c|c|c|c|}
\hline & No of fallers & No of fractures & $\%$ Fractures \\
\hline \multicolumn{4}{|l|}{ Age in years $\dagger$} \\
\hline$\leqslant 60$ & 21 & 1 & 4.8 \\
\hline $61-70$ & 46 & 2 & 4.3 \\
\hline $71-80$ & 180 & 14 & 7.8 \\
\hline $81-90$ & 329 & 19 & 5.8 \\
\hline $90+$ & 104 & 13 & 12.5 \\
\hline \multicolumn{4}{|l|}{ Gender } \\
\hline Women & 443 & 33 & 7.4 \\
\hline Men & 262 & 17 & 6.5 \\
\hline \multicolumn{4}{|c|}{ Hip protector status } \\
\hline $\begin{array}{l}\text { User-not } \\
\text { wearing protector }\end{array}$ & 84 & 13 & 15.5 \\
\hline $\begin{array}{l}\text { User-wearing } \\
\text { protector }\end{array}$ & 191 & 10 & 5.2 \\
\hline Non-user & 430 & 27 & 6.3 \\
\hline Total & 705 & 50 & 7.1 \\
\hline
\end{tabular}

of that among the non-wearers among the registered users (table 1). The corresponding odds from the logistic regression confirms this result ("user-wearing protector", OR 0.31 , $\mathrm{p}=0.009$, "non-users", OR 0.37, p=0.006, table 2). "Usernot wearing protector" was slightly older (not significant) and had a slightly higher percentage of men (not significant) than "user-wearing protector" (data not shown, mean age (\% men) 84 (35) and 83 (33), respectively). Age and gender had no influence on risk of hip fracture (table 2 ).

Of the 84 users not wearing the hip protector, six residents (that is, $7 \%$ ) had the protector actually on their knees while they were dressing or undressing. The fall resulted in a broken hip for three of them. When including a variable called "hip protector on the knees" in the logistic regression, this new variable achieved an OR of 10.35 (95\% confidence interval (CI ) 1.54 to 69.77) in comparison with "user-not wearing protector". With this variable included, the variable "user-wearing protector" achieved an OR of 0.38 (95\% CI 0.15 to 0.956 ) and the variable "non-user" achieved an OR of 0.46 (95\% CI 0.21 to 0.998$)$.

Thirty nine percent of the residents with at least one fall were registered users at the time of their first fall (table 3:

Table 2 The odds ratio (OR) of breaking the hip in the first registered fall within each of 705 fallers in 15 nursing homes in two municipalities in Norway in 1998/99 depending on hip protector status, estimated by means of logistic regression adjusted for age and gender

\begin{tabular}{|c|c|c|c|}
\hline & OR & p Value & $95 \% \mathrm{Cl}$ \\
\hline \multicolumn{4}{|l|}{ Age } \\
\hline One year increase & 1.017 & 0.35 & 0.98 to 1.05 \\
\hline Ten year increase & 1.18 & 0.35 & 0.83 to 1.69 \\
\hline \multicolumn{4}{|l|}{ Gender } \\
\hline Women $=1$, men $=0$ & 1.07 & 0.84 & 0.57 to 2.00 \\
\hline \multicolumn{4}{|l|}{ Hip protector status } \\
\hline $\begin{array}{l}\text { User-not wearing } \\
\text { protector }(\mathrm{Yes}=1, \mathrm{No}=0)\end{array}$ & 1.00 & & \\
\hline $\begin{array}{l}\text { User-wearing } \\
\text { protector }(Y e s=1, N o=0)\end{array}$ & 0.31 & 0.009 & 0.13 to 0.75 \\
\hline $\begin{array}{l}\text { Non-user (Yes }=1 \text {, } \\
\mathrm{No}=0 \text { ) }\end{array}$ & 0.37 & 0.006 & 0.18 to 0.75 \\
\hline
\end{tabular}




\begin{tabular}{|c|c|c|c|}
\hline & No of fallers & No of fractures & $\%$ Fractures \\
\hline \multicolumn{4}{|l|}{ First fall } \\
\hline $\begin{array}{l}\text { User-not wearing } \\
\text { protector }\end{array}$ & 84 & 13 & 15.5 \\
\hline $\begin{array}{l}\text { User-wearing } \\
\text { protector }\end{array}$ & 191 & 10 & 5.2 \\
\hline Non-user & 430 & 27 & 6.3 \\
\hline $\begin{array}{l}\text { Total } \\
\text { Second fall }\end{array}$ & \multicolumn{2}{|c|}{ Second fall } & 7.1 \\
\hline $\begin{array}{l}\text { User-not wearing } \\
\text { protector }\end{array}$ & 49 & 2 & 4.1 \\
\hline $\begin{array}{l}\text { User-wearing } \\
\text { protector }\end{array}$ & 140 & 1 & 0.7 \\
\hline Non-user & 163 & 3 & 1.8 \\
\hline \multicolumn{4}{|l|}{ Third fall } \\
\hline $\begin{array}{l}\text { User-not wearing } \\
\text { protector }\end{array}$ & 37 & 2 & 5.4 \\
\hline $\begin{array}{l}\text { User-wearing } \\
\text { protector }\end{array}$ & 101 & 0 & 0 \\
\hline Non-user & 94 & 1 & 1.1 \\
\hline & \multicolumn{3}{|c|}{ Fourth fall } \\
\hline $\begin{array}{l}\text { User-not wearing } \\
\text { protector }\end{array}$ & 29 & 1 & 3.4 \\
\hline $\begin{array}{l}\text { User-wearing } \\
\text { protector }\end{array}$ & 75 & 1 & 1.3 \\
\hline Non-user & 69 & 2 & 2.9 \\
\hline Total & 173 & 4 & 2.3 \\
\hline
\end{tabular}

$(84+191) / 705=39 \%)$. At the time of the second fall among those with at least two falls, 54\% were registered as daily users (table 3 ). The corresponding numbers at the third and fourth fall were $59 \%$ and $60 \%$, respectively (table 3 ). The percentages of hip fracture were around three times higher in the first fall than in the second, third, and fourth falls (table 3).

Six of the residents, who broke the hip in the first fall, had a second fall, and one of them broke the hip once again. There were two residents among the 705 fallers who broke their hip twice: one of them had two falls and broke the hip each time, the other one had five falls and broke the hip in the fourth and the fifth falls (data not shown). Both these residents were non-users of hip protectors at the time of the first hip fracture, but were registered as users and did wear a hip protector in their next fall when they once again broke a hip. All the other 703 fallers had at most one hip fracture during the intervention period.

The registered users of hip protectors not wearing a hip protector when they fell had the highest unadjusted risk of hip fracture both in the first, second, third, and the fourth fall compared with those who wore the hip protector and compared with those who were non-users (table 3 ). The users wearing a hip protector when they fell had a lower percentage of hip fracture than the group judged to be in no need of a hip protector (table 3 ).

\section{DISCUSSION}

In this intervention to prevent hip fractures in nursing homes we found that the odds of suffering a hip fracture was reduced to less than a third in protected falls compared with unprotected falls. This odds ratio yielded persons at high risk of suffering a hip fracture-that is, persons judged by the residents themselves and the employees to be fragile and in special need of hip protectors. The fallers who wore a hip protector when they fell achieved a reduction in hip fracture risk to a risk level lower than the level for those who were judged to be in no need of a hip protector (tables 1-3).

Kannus et al showed a stronger preventive effect of the hip protector in their hip protector group. ${ }^{7}$ In their study, the relative hazard of hip fracture in falls with the hip protector on compared with falls with the hip protector off was relative hazard 0.2 (95\% CI 0.05 to 0.5 ) unadjusted and relative hazard 0.1 ( $95 \%$ CI 0.03 to 0.5 ) adjusted for confounders. The participants were specially selected-for example, the participants had to be ambulatory and written consent for each participant had to be given. Their user group (which included both nursing home residents and the home dwelling elderly) was probably not as fragile as our user group. The Kannus study had 2.43 fractures per 100 falls among the non-wearers in the user group, while we had 15.5 among the non-wearers among the registered users (table 1 ). The corresponding numbers for the wearers were 0.39 and 5.2 fractures per 100 falls respectively. (However, this comparison may be uncertain because of the uncertainty about missing falls in the two studies, but the user groups in both studies were comparable in the sense that both were judged to be in need of hip protectors.)

The effectiveness of the hip protector may not be as good when implemented in the rough and tumble of routine practice $^{8}$ where the hip protector is offered to every resident in the nursing homes irrespective of their walking ability ${ }^{9}$ and where no written consent is needed. Our intervention was carried through in a "real world" setting-a translation of health promotion research to practice. ${ }^{10}$ However, our odds ratio was nearly as good as the unadjusted relative hazard in the Kannus et al paper and in a recent paper by Cameron et al studying frail older women living in their own homes. ${ }^{11}$

At the time when it was uncertain whether the hip protector was able to prevent hip fracture, it was ethical to randomise people to a user group or to a non-user group. However, it has never been ethical to randomise wearing of a hip protector in a given fall, because we cannot push old people to see whether they break their hip. Therefore studies about risk of hip fracture in protected and unprotected falls have to be observational. Thus, none of the randomised, controlled hip protector trials have randomised when they analyse protected and unprotected falls. In these analyses they use only the intervention group.

Eventual bias in the risk estimates in such observational studies can be reduced if one is able to adjust for frailty in the model. Kannus et al adjusted for body mass index, mental status, ability to walk, previous falls, and previous fractures, which strengthened the result (relative hazard unadjusted 0.2 , relative hazard adjusted 0.1). A limitation of our study was that we were not able to adjust for frailty in this way, but the following three arguments support our statement that the group "user-not wearing protector" was not frailer than the group "user-wearing protector".

Argument 1: The "reasons" for not wearing the hip protector at the time of the fall, registered by the employees, did not indicate a frailer group "user-not wearing protector". The reasons for not wearing hip protector among some of the users were, for example: (1) The resident did not find a hip protector the day of the fall. (2) The resident had taken off the hip protector for the night. (3) A hip protector was not given to him or her the day of the fall. (4) The hip protector was temporarily taken away because of heat rash and so on. None of the registered reasons had any connection with frailty.

Argument 2: On the contrary it has been shown that fallers have a tendency to want to use the hip protector, ${ }^{12}$ which means that our "user-wearing protector" group should 


\section{Key points}

- To prevent hip fracture by hip protectors, our health promotion research in an everyday life setting shows nearly as good results as randomised controlled trials.

- In the "real world" a person at high risk of hip fracture in a nursing home may decrease the risk to a third by using a hip protector.

- When a person is so osteoporotic that the hip can break just by walking, or the person falls backward, the hip protector cannot protect effectively against hip fracture.

- Dressing and undressing may be a high risk situation for a high risk person; the hip protector may cause a loss of balance and a hip fracture may occur.

contain more fallers, and thus more frail individuals than the "user-not wearing protector" group.

Argument 3: The employees were instructed to be especially aware of those at particularly high risk, and to try to convince them of the benefit of using the protector. Thus we may argue that those in the group "user-wearing protector" were even frailer than in the group "user-not wearing protector" because they were wearing their hip protector. That the wearers could be frailer than the non-wearers among the users is in agreement with the Kannus paper. ${ }^{7}$ Their unadjusted result was underestimated compared with the adjusted result. It could be the same in our study; in other words the effect of hip protectors in our study is probably underestimated.

The slightly higher mean age of the group "user-not wearing protector" (not significant) had probably no importance for the difference in frailty since adjusting for age in addition had no effect on the hip fracture odds ratio. The usual age and gender influence on risk of hip fracture is probably absent in our data because it is the old person's health status, frailty, and ability to take care of her/himself which is decisive for admittance to nursing homes. In Norway elderly people stay in their own homes as long as possible.

The compliance in use of hip protectors in this paper is measured by means of the percentage of wearers in the first fall among the registered users $(70 \%)$. This is nearly as good as in the paper of Kannus et al where 74\% (1034/1404) of the falls in the hip protector group occurred with the hip protector on. ${ }^{7}$ In our study there was an increasing percentage of registered users from $39 \%$ to $60 \%$ from the first to the fourth fall within same person. This shows that the employees were following the instructions about being especially aware of the frequent fallers.

The number of missing falls in our study is unknown, but $10 \%$ of the first registered falls had no information of hip protector status. In reality, some of the first registered falls may be a second or a later fall during the intervention period because the first falls may be among the missing falls. The implication of this problem is uncertain, but we have no reason to believe that the missing registrations had anything to do with the hip protector. The more serious the fall, presumably the higher the probability of registration; all the falls which resulted in a hip fracture were registered.

By using only the first registered fall we get around some statistical problems, for example the non-independence of falls within subject and the change of exposure status for subjects sustaining a hip fracture. In the literature there are also others arguing that it makes more sense to examine and analyse each fall within a person separately than putting all the falls into the same analysis. ${ }^{13}$

We know that one particular woman among the 10 residents (in table 2) who suffered a hip fracture was wearing the hip protector and broke her hip before she fell. She was walking, holding the arms of her son and daughterin-law, when she slowly sank to the floor while they held her. However, we could not remove her from the computation of odds ratio, although we knew that she had broken her hip before she fell. If we had been able to remove such persons from the analysis, the estimated protective effect of the hip protector would have been stronger than shown in table 2 . Very osteoporotic people are a part of the real world. It is impossible to pick them out beforehand and they should therefore not be removed from the computation.

The percentages of fracture were much lower in the second, third, and fourth fall compared with the first fall (table 3). It is well known that the frequent fallers are at especially high risk of hip fracture. An explanation to this paradox is presumably that the most frail among the 705 fallers broke the hip in their first fall. Some of the most frail did not come back because they died after the hip fracture-or many days elapsed before they were on their feet again-perhaps not until after the intervention period had ended.

Obviously dressing or undressing increases the risk of a person losing his or her balance and thereby increases tremendously the risk of breaking the hip. Six of the fallers had lost their balance while changing clothes in their first fall and consigned themselves thereby to the group "user-not wearing protector". Residents who have problems with changing clothes should get help each time they are going to take the protector on or off. Such persons probably need help with other clothes as well to prevent losing their balance, but in a busy nursing home such help can be difficult to achieve. It is indeed a paradox that the hip protector may have caused three hip fractures. But at the same time they also prevented about 19 hip fractures $(15.5 \%-5.2 \%=10.3 \%$ of 191 in table 1$)$.

To save residents in nursing homes from getting a painful hip fracture, we should concentrate on the following tasks:

- To encourage and motivate residents with osteoporosis and/or a tendency to fall to wear a hip protector of proven protective effect.

- To improve compliance of hip protector use by increasing comfort and ease of use without losing the protective effect.

- To ensure that those who uses hip protectors are able to put the protector on and take it off without losing balance.

- To construct an evidence based checklist to pick out persons at high risk.

- To make the different hip protectors cheap/free of charge for those at high risk only after a randomised control trial has proved their effectiveness.

- To prevent low bone mineral density and to prevent falling: because the hip protector cannot prevent hip fracture entirely.

The better we succeed in this work during the next decades the better we will be prepared to meet the problems with the increasingly large proportion of elderly people at high risk of hip fracture.

\section{ACKNOWLEDGEMENTS}

We want to thank Asker and Bærum municipalities, Akershus County Administration, and Bærum Hospital for financing the project. We also want to thank the employees and residents at the participating nursing homes. The authors have no conflict of interest/ competing interest with respect to the studied hip protector. 


\section{Authors' affiliations}

L Forsén, A J Søgaard, C Arstad, Norwegian Institute of Public Health, Oslo, Norway

S Sandvig, U Røed, County of Akershus and the municipalities of Asker and Bærum, Norway

A Schuller, TNO Prevention and Health, Leiden, The Netherlands

\section{REFERENCES}

1 Grisso JA, Kelsey JL, Strom BL, et al. Risk factors for falls as a cause of hip fracture in women. The Northeast Hip Fracture Study Group. N Engl J Med 1991;324:1326-31.

2 Parkkari J, Kannus P, Palvanen M, et al. Majority of hip fractures occur as a result of a fall and impact on the greater trochanter of the femur: a prospective controlled hip fracture study with 206 consecutive patients. Calcif Tissue Int 1999;65:183-7.

3 Parker MJ, Gillespie LD, Gillespie WJ. Hip protectors for preventing hip fractures in the elderly (Cochrane Review). Cochrane Database Syst Rev 2002;(2):CD001255

4 Meyer G, Warnke A, Bender R, et al. Effect on hip fractures of increased use of hip protectors in nursing homes: cluster randomised controlled trial [comment]. BMJ 2003;326:76.
5 Lauritzen JB, Petersen MM, Lund B. Effect of external hip protectors on hip fractures [see comments]. Lancet 1993;341:11-3.

6 Forsén L, Arstad C, Sandvig S, et al. Prevention of hip fracture by external hip protectors. An intervention in 17 nursing homes in two municipalities in Norway. Scandinavian Journal of Public Health 2003;31:264-6.

7 Kannus P, Parkkari J, Niemi S, et al. Prevention of hip fracture in elderly people with use of a hip protector [see comments]. N Engl J Med 2000;343:1506-13.

8 Torgerson D, Birks Y. Purity, pragmatism and hip protector pads [letter to the editor]. Age Ageing 2002;31:319-25.

9 Campbell AJ. Purity, pragmatism and hip protector pads [editorial]. Age Ageing 2001;30:431-2.

10 Glasgow RE, Lichtenstein E, Marcus AC. Why don't we see more translation of health promotion research to practice? Rethinking the efficacy-to-effectiveness transition. Am J Public Health 2003;93:1261-7.

11 Cameron ID, Cumming RG, Kurrle SE, et al. A randomised trial of hip protector use by frail older women living in their own homes. Inj Prev 2003:9:138-41.

12 Thompson PW, Jones C. Adherence to hip protector use in elderly people requiring domicilary care is greater in fallers than non-fallers [letter; comment]. Age Ageing 2000;29:459

13 Cumming RG, Kelsey JL, Nevitt MC. Methodologic issues in the study of frequent and recurrent health problems. Falls in the elderly [comment]. Ann Epidemiol 1990;1:49-56. 